\section{Dual Mobility Acetabular - Cup Total Hip Arthroplasty after Femoral Neck Fracture in the Elderly: Prospective Study on Risks of Early Dislocation in 80 Total Hip Replacements}

\author{
K Lahrach ${ }^{1,2 *}$, S Abdulrazak ${ }^{1}$, A Marzouki ${ }^{1}$ and F Boutayeb ${ }^{1}$ \\ ${ }^{1}$ Department of Trauma and Orthopedic Surgery A, Hassan II Teaching \\ Hospital, Fes, Morocco
}

${ }^{2}$ Faculty of Medicine and Pharmacy, Sidi Mohammed Ben Abdellah University, Fes, Morocco

\begin{abstract}
Background: Total Hip Arthroplasty (THA) for femoral neck fractures in the elderly is still lauded as one of the most successful surgeries of the century with good short and medium term outcomes. Postoperative dislocation remains the mainset back of hip replacement in the elderly. This study mainly sees keto assess early outcomes of total hiparthroplasty using dual mobility acetabular cup for femoral neckfractures in the elderly with emphasis ondislocation.

Patients and Methods: We carried out 80 consecutive total hip replacements using a double articulating acetabular component. We assessed dislocation rates after 6 months and cumulative risks in the years following replacement.

Results: After a mean follow-up of 50 months, only $8(10 \%)$ deaths were recorded. We observed 1 case of dislocation at 4 months postoperatively that required revision arthroplasty. No case of instability was recorded.
\end{abstract}

Conclusion: Dual mobility acetabular cups remain suitable implants in the face of postoperative dislocation after total hip replacement for femoral neck fractures in the elderly.

Keywords: Dislocation; Dual mobility cup; Femoral neck fracture

*Corresponding author: K Lahrach, Department of Trauma and Orthopedic Surgery A, Hassan II Teaching Hospital, Faculty of Medicine and Pharmacy, Sidi Mohammed Ben Abdellah University, Fes, Morocco, E-mail: k.lahrach@hotmail.com

Citation: Lahrach K, Abdulrazak S, Marzouki A, Boutayeb F (2019) Dual Mobility Acetabular - Cup Total Hip Arthroplasty after Femoral Neck Fracture in the Elderly: Prospective Study on Risks of Early Dislocation in 80 Total Hip Replacements. J Orthop Res Physiother 5: 041.

Received: March 13, 2019; Accepted: April 17, 2019; Published: April 25, 2019

Copyright: (c) 2018 Lahrach K, et al., This is an open-access article distributed under the terms of the Creative Commons Attribution License, which permits unrestricted use, distribution, and reproduction in any medium, provided the original author and source are credited.

\section{Introduction}

Femoral neck fractures in the elderly are generally treated by partial or total hip replacement with early dislocation rates generally around $2-3 \%$ [1].The authors intend to demonstrate the efficacy of dual mobility cups for total hip replacement in the prevention of postoperative dislocation.

\section{Patients and methods}

We conducted a prospective study, comprising 80 consecutive dual mobility total hip replacements carried out at the Department of Trauma and Orthopedic Surgery A, from January 2010 to December 2017, for older patients with femoral neck fracture (Figure 1 and 2).

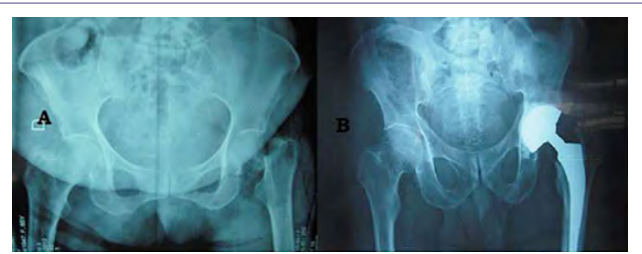

Figure 1: (A) preoperative X-ray showing a displaced femoral neck fracture in a 65 year old woman who underwent hybrid total hip arthroplasty using dual mobility cemented cup (B).

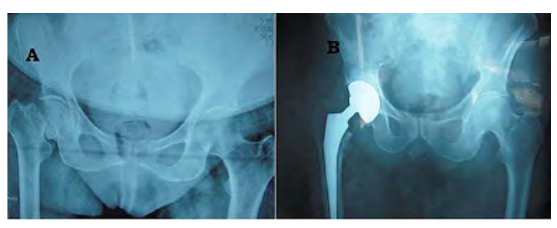

Figure 2: (A) 68 year old semi-autonomous man who suffered a right side Trans cervical fracture and underwent cement less total hip arthroplasty with dual mobility acetabular cup (B).

We included in this case series all patients who underwent primary THA for femoral neck fractures aged above 55 years. Thus we excluded all cases of neglected femoral neck fractures and cases associated with femoral shaft fractures.

54 women and 26 men, aged between 60 and 90 years with right side femoral neck fractures in $65 \%$ of cases were involved. $79 \%$ of the patients were autonomous with aided ambulation prior to injury. Parker score averaged 5/9. Average time between fracture and surgery was 3 days.

THA was done mostly underspinal anesthesia $(\mathrm{n}=7087.5 \%)$ with patient in a lateral decubitus position using a modified posterolateral Moore (Southern) approach in all cases.Dual mobility THA applying Charnley's low friction torque principle using a $28 \mathrm{~mm}$ diameter head that articulates against polyethylene to decrease wear with a secondary larger diameter articulation between polyethylene liner and metal shell of acetabular component furtherenhancing implant stability (Figure 3 and 4 ) was carried out. Acetabular component was cemented in $75 \%$ of the cases. 


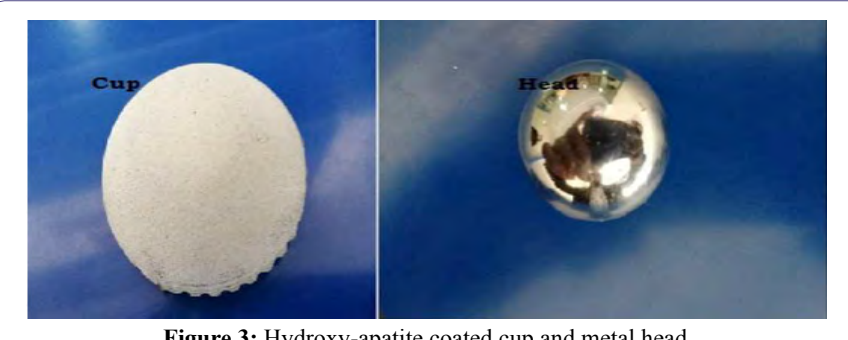

Figure 3: Hydroxy-apatite coated cup and metal head.

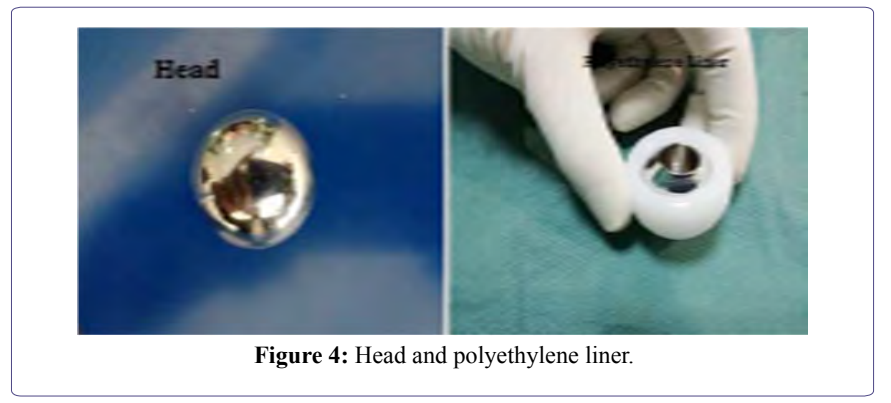

Rehabilitation was commenced after the first postoperative day withfull weight bearing and braced ambulation. Patients were discharged on the third postoperative day with leaflets explaining prohibited maneuvers and physical therapy protocol.

Follow-up was carried out monthly up to 6 months and twice yearly afterwards with routine $\mathrm{x}$-rays and physical exams.The Merle d'Aubigné and Postel hip score was used to assess outcomes after THA. We also assessed cumulative risks of dislocations in the years following replacement.

\section{Results}

80 patients predominantly women (sex ratio $2: 1$ ) were hospitalized for femoral neck fractures after standing fall in most cases (78\%). Average time between injury and surgery was 3 days. 35 patients were diabetic, 60 patients were hypertensive whereas 17 patients had chronic renal failure on admission. The following table highlights radiographic outcomes after THA (Table 1).

\begin{tabular}{|c|c|c|c|c|c|}
\hline $\begin{array}{c}\text { Number } \\
\text { of Patients }\end{array}$ & $\begin{array}{c}\text { Indications } \\
\text { of THA }\end{array}$ & $\begin{array}{c}\text { Femoral } \\
\text { Head size }\end{array}$ & $\begin{array}{c}\text { Acetabular } \\
\text { component tilt }\end{array}$ & Anteversion & Cemented \\
\hline 80 & $\begin{array}{c}\text { Femoral } \\
\text { neck } \\
\text { fractures }\end{array}$ & $28 \mathrm{~mm}$ & $40 \pm 5^{\circ}$ & $15 \pm 5^{\circ}$ & 60 \\
\hline
\end{tabular}

Table 1: Acetabular cup orientation and primary fixation.

After a mean follow-up of 50 months (between 12 and 65 months), we observed a single case of dislocation at 4 months postoperatively, following a fall that required open reduction (Figure 5). A single case of deep venous thrombosis of the lower limb was managed with heparin with favorable outcome. We recorded $8(10 \%)$ deaths on the last follow-up. 5 cases were due to acute kidney failure, 3 due to congestive heart disease. No case of instability or atraumatic dislocation wasreported. No cases of acetabular or femoral implant loosening have been reported on postoperative radiography during this period.
The Merle d'Aubigné and Postel score averaged 15.8 versus 7.2 preoperatively.

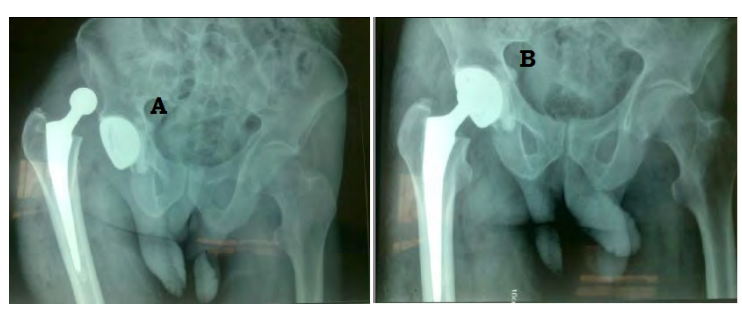

Figure 5: Hip x-ray showing dislocation on hip replacement (A) reduced after closed reduction $(\mathrm{B})$.

\section{Discussion}

Femoral neck fracture is a very common pathology of the elderly. Usually associated with osteoporosis, it mainly affects $70 \%$ of women above 80-years-old [2].

Choice of implant in primary hip replacement for femoral neck fractures remains a popular source of debate among orthopedic surgeons. Many often divided along the lines of either partial or total arthroplasty in what is a population with low life expectancy. Factors that may affect the stability after THA include surgical approach, patient-related factors like neurological disorders component orientation and geometry, and more particularly, head diameter and headneck ratio [3].The use of low friction torque and dual mobility cups has gained popularity recently under several designations and descriptions including "unconstrained tripolar cups" and "mobile bearing cups" by manufacturers $[4,5]$.

In our study postoperative mortality at 3 months was similar to rates reported by similar prospective studies of femoral neck fractures in the elderly. Skinner, et al., [6] observed that mortality rate was identical between partial and total arthroplasty for displaced femoral neck fractures in the elderly. Nonetheless some authors have reported dislocation rates up to 4 times higher in hemiarthroplasty after femoral neck fractures [7].

Dislocation rates following primary THA is estimated at $2.2 \%$ after one year, $3.8 \%$ at ten years, reaching up to $6 \%$ after 20 years [8]. A meta-analysis [9] observed an average dislocation rate of $10.7 \%$, five times higher than primary replacement for degenerative osteoarthritis. Althoughcerebral palsy, Parkinson's disease, poliomyelitis and history of cerebrovascular accident, spinal injury or Charcot arthropathy are risk factors for instability,early dislocation is directly linked to surgical approach and component positioning. Popular theory suggests a decrease in muscle control associated with ligamentous laxity following femoral neck fracturesin elderly patients [10]. Dual mobility cups have gained more interestin primary replacement for femoral neck fractures and revision arthroplasty as they exhibit less wear, restore near normal range of motion with increased implant stability $[11,12]$.

The concept of dual mobility was developed initially by Bousquet in the late 1970s. Its main purpose was to prevent dislocation by combining two articulating systems, one with a large diameter, between a metal cup and a polyethylene liner, and the other with a small diameter between the femoral head and its retentive insert. Generally, as 
Citation: Lahrach K, Abdulrazak S, Marzouki A, Boutayeb F (2019) Dual Mobility Acetabular - Cup Total Hip Arthroplasty after Femoral Neck Fracture in the Elderly: Prospective Study on Risks of Early Dislocation in 80 Total Hip Replacements. J Orthop Res Physiother 5: 041.

rule of thumb the use of large diameter femoral head could address the problem of instability and mechanical studies have exhibited low dislocation rates with $28 \mathrm{~mm}$ femoral head components [13-15].This concept does not exhibit complications pertaining to simple implant retention, which solicits attachment through bony press fit, with less wear as the larger joint allowed additional range of motion during dislocation manoeuvers. Pituckanotai, et al., [16] in a recent network meta-analysis recommend dual mobility and big head as safer implants in THA with less risk of dislocation and revision.

Studies assessing survivorship of dual-articulation acetabular cup systems have reported good long-term results. The main drawback of hybrid primary THA remains aseptic loosening [17]. Tripolar prosthesis with a mobile cup and large-diameter heads are also deemed a reliable solution in highly unstable hips though the thickness of the polyethylene cup presents a considerable limitation which may affect long-term outcome due to a higher risk of wear [18]. A study by Tarasevicius [19] involving 42 patients who underwent dual mobility THA did not report any case of postoperative dislocation.

\section{Conclusion}

Surgical management of femoral neck fractures in the elderly by total hip arthroplasty has demonstrated excellent short term outcomes in terms of stable painless hip function. Dual mobility acetabular cups remain suitable implants in the face of postoperative dislocation after total hip replacement for femoral neck fractures.

\section{List of abbreviations}

THA: Total Hip Arthroplasty.

\section{Declarations}

\section{Ethics approval and consent to participate}

Local ethics committee approval was sought before the publication of this article.

\section{Consent to publish}

Written informed consent was obtained from the patients involved in this case series for publication of this article and associated images.

\section{Availability of data and materials}

Not applicable.

\section{Competing interests}

The authors declare no potential conflicts of interest with respect to the authorship, and/or publication of this article.

\section{Funding}

Not applicable.

\section{Author's Contributions:}

All authors contributed either directly or indirectly in the writing and general format of the manuscript.

\section{References}

1. Berry DJ, von Knoch M, Schleck CD, Harmsen WS (2004) The cumulative long-term risk of dislocation after primary Charnley total hip arthroplasty. J Bone Joint Surg Am 86: 9-14.
2. Marottoli RA, Berkman LF, Cooney LM (1992) Decline in physical function following hip fracture. J Am Geriatr Soc 40: 861-866.

3. Philippot R, Camilleri JP, Boyer B, Adam P, Farizon F (2009) The use of a dual-articulation acetabular cup system to prevent dislocation after primary total hip arthroplasty: Analysis of 384 cases at a mean follow-up of 15 years. Int Orthop 33: 927-932.

4. Roberts KC, Brox WT, Jevsevar DS, Sevarino K (2015) Management of hip fractures in the elderly. J Am Acad Orthop Surg 23: 131-137.

5. Guyen O, Chen QS, Bejui-Hugues J, Berry DJ, An KN (2007) Unconstrained tripolar hip implants: effect on hip stability. Clin Orthop Relat Res 455: 202-208.

6. Skinner P, Riley D, Ellery J, Beaumont A, Coumine R, et al. (1989) Displaced subcapital fractures of the femur: A prospective randomized comparison of internal fixation, hemiarthroplasty and total hip replacement. Injury 20: 291-293.

7. Gjertsen JE, Vinje T, Lie SA, Engesaeter LB, Havelin LI, et al. (2008) Patient satisfaction, pain, and quality of life 4 months after displaced femoral neck fractures: A comparison of 663 fractures treated with internal fixation and 906 with bipolar hemiarthroplasty reported to the Norwegian Hip Fracture Register. Acta Orthop 79: 594-601.

8. Berry DJ, Vonknoch M, Schleck CD, Harmsen WS (2005) Effect of femoral head diameter and operative approach on risk of dislocation after primary total hip arthroplasty. J Bone Joint Surg Am 87: 2456-2463.

9. Iorio R, Healy WL, Lemos DW, Appleby D, Lucchesi CA, et al (2001) Displaced femoral neck fractures in the elderly: outcomes and cost effectiveness. Clin Orthop Relat Res 383: 229-242.

10. Hudson JI, Kenzora JE, Hebel JR, Gardner JF, Scherlis L, et al. (1998) Eight- year outcome associated with clinical options in the management of femoral neck fractures. Clin Orthop Relat Res 348: 59-66.

11. Lebeau N, Bayle M, Belhaouane R, Chelli M, Havet E, et al. (2017) Total hip arthroplasty revision by dual-mobility acetabular cup cemented in a metal reinforcement: A 62 case series at a minimum 5 years' follow-up. Orthop Traumatol Surg Res 103: 679-684.

12. Darrith B, Courtney PM, Della Valle CJ (2018) Outcomes of dual mobility components in total hip arthroplasty: A systematic review of the literature. Bone Joint J 100: 11-19.

13. Lombardi AV Jr, Skeels MD, Berend KR, Adams JB, Franchi OJ (2011) Do large heads enhance stability and restore native anatomy in primary total hip arthroplasty? Clin Orthop Relat Res 469: 1547-1553.

14. Pedersen DR, Callaghan JJ, Johnston TL, Fetzer GB, Johnston RC (2001) Comparison of femoral head penetration rates between cementless acetabular components with 22-mm and 28-mm heads. J Arthroplasty 16: 111115 .

15. Kelley SS, Lachiewicz PF, Hickman JM, Paterno SM (1998) Relationship of femoral head and acetabular size to the prevalence of dislocation. Clin Orthop Relat Res 355: 163-70.

16. Pituckanotai K, Arirachakaran A, Tuchinda H, Putananon C, Kongtharvonskul J, et al. (2018) Risk of revision and dislocation in single, dual mobility and large femoral head total hip arthroplasty: systematic review and network meta-analysis. Eur J Orthop Surg Traumatol 28: 445-455.

17. Aubriot JH, Lesimple P, Leclercq S (1993) Study of Bousquet's non-cemented acetabular implant in 100 hybrid total hip prostheses (Charnley type cemented femoral component). Average 5-year follow-up. Acta Orthop Belg 59: 267-271.

18. Beaule PE, Roussignol X, Schmalzried TP, Udomkiat P, Amstutz HC, et al. (2003) Tripolararthroplasty for recurrent total hip prosthesis dislocation. Rev Chir Orthop Reparatrice Appar Mot 89: 242-249.

19. Tarasevicius S, Busevicius M, Robertsson O, Wingstrand H (2010) Dual mobility cup reduces dislocation rate after arthroplasty for femoral neck fracture. BMC Musculoskelet Disord 11: 175. 


\section{Hit}

Journal of Anesthesia \& Clinical Care

Journal of Addiction \& Addictive Disorders

Advances in Microbiology Research

Advances in Industrial Biotechnology

Journal of Agronomy \& Agricultural Science

Journal of AIDS Clinical Research \& STDs

Journal of Alcoholism, Drug Abuse \& Substance Dependence

Journal of Allergy Disorders \& Therapy

Journal of Alternative, Complementary \& Integrative Medicine

Journal of Alzheimer's \& Neurodegenerative Diseases

Journal of Angiology \& Vascular Surgery

Journal of Animal Research \& Veterinary Science

Archives of Zoological Studies

Archives of Urology

Journal of Atmospheric \& Earth-Sciences

Journal of Aquaculture \& Fisheries

Journal of Biotech Research \& Biochemistry

Journal of Brain \& Neuroscience Research

Journal of Cancer Biology \& Treatment

Journal of Cardiology: Study \& Research

Journal of Cell Biology \& Cell Metabolism

Journal of Clinical Dermatology \& Therapy

Journal of Clinical Immunology \& Immunotherapy

Journal of Clinical Studies \& Medical Case Reports

Journal of Community Medicine \& Public Health Care

Current Trends: Medical \& Biological Engineering

Journal of Cytology \& Tissue Biology

Journal of Dentistry: Oral Health \& Cosmesis

Journal of Diabetes \& Metabolic Disorders

Journal of Dairy Research \& Technology

Journal of Emergency Medicine Trauma \& Surgical Care

Journal of Environmental Science: Current Research

Journal of Food Science \& Nutrition

Journal of Forensic, Legal \& Investigative Sciences

Journal of Gastroenterology \& Hepatology Research

Journal of Gerontology \& Geriatric Medicine
Journal of Genetics \& Genomic Sciences

Journal of Hematology, Blood Transfusion \& Disorders

Journal of Human Endocrinology

Journal of Hospice \& Palliative Medical Care

Journal of Internal Medicine \& Primary Healthcare

Journal of Infectious \& Non Infectious Diseases

Journal of Light \& Laser: Current Trends

Journal of Modern Chemical Sciences

Journal of Medicine: Study \& Research

Journal of Nanotechnology: Nanomedicine \& Nanobiotechnology

Journal of Neonatology \& Clinical Pediatrics

Journal of Nephrology \& Renal Therapy

Journal of Non Invasive Vascular Investigation

Journal of Nuclear Medicine, Radiology \& Radiation Therapy

Journal of Obesity \& Weight Loss

Journal of Orthopedic Research \& Physiotherapy

Journal of Otolaryngology, Head \& Neck Surgery

Journal of Protein Research \& Bioinformatics

Journal of Pathology Clinical \& Medical Research

Journal of Pharmacology, Pharmaceutics \& Pharmacovigilance

Journal of Physical Medicine, Rehabilitation \& Disabilities

Journal of Plant Science: Current Research

Journal of Psychiatry, Depression \& Anxiety

Journal of Pulmonary Medicine \& Respiratory Research

Journal of Practical \& Professional Nursing

Journal of Reproductive Medicine, Gynaecology \& Obstetrics

Journal of Stem Cells Research, Development \& Therapy

Journal of Surgery: Current Trends \& Innovations

Journal of Toxicology: Current Research

Journal of Translational Science and Research

Trends in Anatomy \& Physiology

Journal of Vaccines Research \& Vaccination

Journal of Virology \& Antivirals

Archives of Surgery and Surgical Education

Sports Medicine and Injury Care Journal

International Journal of Case Reports and Therapeutic Studies 